\title{
O ESTADO DO CONHECIMENTO SOBRE A FORMAÇÃO DE PROFESSORES DE MATEMÁTICA NOS INSTITUTOS FEDERAIS
}

\author{
EL ESTADO DEL CONOCIMENTO SOBRE LA FORMACIÓN DE \\ PROFESORES DE MATEMÁTICAS EM INSTITUTOS FEDERALES
}

\section{THE STATE OF KNOWLEDGE ABOUT THE TRAINING OF MATHEMATICS TEACHERS IN FEDERAL INSTITUTES}

Leandro de Jesus Dueli Instituto Federal de Educação, Ciência e Tecnologia de Goiás - IFG

Maria Jesus Salinas Portugal

Universidade de Santiago de Compostela - USC

Simone Ariomar de Souza Instituto Federal de Educação, Ciência e Tecnologia de Goiás - IFG

\begin{abstract}
RESUMO
O presente artigo é parte de uma pesquisa doutoral que tem como objeto de estudo o campo da Formação de Professores no Brasil, em particular a formação ofertada pelos Institutos Federais, criados em 2008. O número de cursos de Licenciatura nesse novo lócus aumentou vertiginosamente nos últimos anos se tornando um ambiente profícuo para investigação, dadas suas peculiares características históricas, políticas e sociais. As pesquisas desenvolvidas a respeito dos cursos de formação de professores de Matemática neste lócus já nos apontam os rumos da formação ofertada, estabelecendo um estado do conhecimento. Observa-se uma formação não muito distante da já ofertada há décadas nas Universidades Federais, o que coloca em (re)discussão as reais motivações para a inserção de Licenciaturas nos Institutos Federais.
\end{abstract}

Palavras-Chave: Formação de Professores. Estado do Conhecimento. Institutos Federais. Rede Federal. 


\title{
O ESTADO DO CONHECIMENTO SOBRE A FORMAÇÃO DE PROFESSORES DE MATEMÁTICA NOS INSTITUTOS FEDERAIS
}

\section{RESUMEN}

Este artículo es parte de una investigación doctoral que tiene como objeto de estudio el campo de la Formación Docente en Brasil, en particular la capacitación ofrecida por los Institutos Federales, creada en 2008. El número de cursos de pregrado en este nuevo locus ha aumentado dramáticamente en los últimos años convirtiéndose en un entorno fructífero para la investigación, dadas sus características históricas, políticas y sociales peculiares. Las investigaciones desarrolladas con respecto a los cursos de formación de profesores de matemáticas en este lugar ya nos indican la dirección de la formación ofrecida, estableciendo un estado de conocimiento. Hay una formación no muy lejos de lo que se ha ofrecido durante décadas en las Universidades Federales, que pone en (re) discusión las motivaciones reales para la inserción de títulos de licenciatura en los Institutos Federales.

Palabras clave: Formación docente. Estado del conocimiento. Institutos Federales. Red Federal.

\begin{abstract}
This article is part of a doctoral research that has as its object of study the field of Teacher Education in Brazil, in particular the training offered by the Federal Institutes, created in 2008. The number of Teaching courses in this new locus has increased dramatically in recent years, becoming a fruitful environment for research, given its peculiar historical, political and social characteristics. The researches developed regarding the mathematics teacher training courses in this locus already point us in the direction of the training offered, establishing a state of knowledge. There is a formation not far from what has been offered for decades at Federal Universities, which puts into (re) discussion the real motivations for the insertion of Teaching courses in Federal Institutes.
\end{abstract}

Keywords: Teacher training. State of Knowledge. Federal Institutes. Federal Network.

\section{INTRODUÇÃO}

A qualidade e a equidade na educação brasileira, tão almejadas por toda a sociedade e preconizadas nas políticas públicas, dependem de vários condicionantes. A criação de uma sólida carreira de magistério, com professores bem formados e profissionalizados, tem sido um dos pontos nevrálgicos ao longo de toda a história da formação de professores no Brasil. Uma das peças centrais, de acordo com Abrúcio (2016), é a formação e o aperfeiçoamento dos docentes, seja dos que vão entrar na carreira, seja dos que nela estão.

O tema da formação de professores, sobretudo no que se refere à qualidade, tem adquirido visibilidade na mídia e se apresenta frequentemente em discursos políticos e de gestores, sobretudo nas últimas duas décadas, devido à provável aposentadoria de um número considerável de professores nos próximos anos, o que pode gerar um "apagão" e as reformas Revista RBBA Revista Binacional Brasil Argentina 


\section{O ESTADO DO CONHECIMENTO SOBRE A FORMAÇÃO DE PROFESSORES DE MATEMÁTICA NOS INSTITUTOS FEDERAIS}

impulsionadas pelo atual Plano Nacional de Educação - PNE (BRASIL, 2014) que estabelece 4 (de um total de 20) metas que dizem respeito à formação de professores. (ABRÚCIO, 2016).

Desta forma, discutir a formação de professores "não se trata simplesmente de abordar um tema de pesquisa", conforme Gatti et al (2019, p. 11) "mas sim de estudar um problema social da maior relevância nos dias atuais". O papel de educadores é central na educação escolar, porém o desafio da profissionalização docente, sobretudo da educação básica, vem se constituindo como um dos mais importantes na agenda mundial de prioridades da UNESCO em decorrência da importância do professor para assegurar uma educação de qualidade para todos, tanto no plano cognitivo quanto na dimensão humanista e ética dessa profissão. Ambas as dimensões, segundo Gatti e Barreto $(2009$, p. 7), integram o "direito subjetivo à educação" que a Declaração Universal dos Direitos Humanos de 1948 consagrou para servir de prérequisito à reconstrução das sociedades em direção a uma cultura de paz.

Diante da importância e relevância deste tema e dos desafios elencados engendramos uma pesquisa doutoral tendo como objeto de estudo o campo da Formação de Professores no Brasil, e em particular nos Institutos Federais de Educação, Ciência e Tecnologia - IF, criados a partir da Lei 11892/2008 (BRASIL, 2008).

O objetivo deste artigo, e um dos objetivos da pesquisa doutoral, é fazer um levantamento e analisar as pesquisas realizadas sobre a formação de professores nos IFs, e em particular de Matemática, em busca do estado do conhecimento da produção científica sobre a formação de professores nos IFs, apontando seu rumo.

A formação de professores na Rede Federal de Educação Profissional, Científica e Tecnológica - REDE não se iniciou em 2008, com o advento dos Institutos Federais, porém se tornou obrigatória a partir deste. A formação de professores na REDE se inicia de fato 30 anos antes, quando da criação dos Centros Federais de Educação Tecnológica - CEFETs, em 1978, porém destinada à formação de professores apenas para disciplinas técnicas.

A Lei 11892/2008, ao criar os IFs, trouxe novidades em comparação com os antigos CEFETs e Escolas Técnicas/Agrotécnicas Federais - ETFs/EAFs. Os IFs passam agora a oferecer obrigatoriamente cursos de Licenciatura, prioritariamente nas áreas de ciências e matemática. Essa obrigatoriedade surge, dentre outros fatores, a partir de um relatório publicado pelo Conselho Nacional de Educação - CNE (BRASIL, 2007b), um ano antes, ou seja, em 2007, que acusava a escassez de professores nessas áreas. Essa novidade fez iniciar uma corrida nos antigos CEFETs, ETFs e EAFs para se adequarem à prerrogativa legal, todos os IFs devem, 


\section{O ESTADO DO CONHECIMENTO SOBRE A FORMAÇÃO DE PROFESSORES DE MATEMÁTICA NOS INSTITUTOS FEDERAIS}

a partir desta lei, ter no mínimo $20 \%$ de suas vagas ofertadas em cursos de Licenciatura, prioritariamente nas áreas de Ciências e Matemática.

Essa prerrogativa legal acaba por criar compulsoriamente um novo lócus de formação de professores no Brasil. Uma instituição que historicamente preparou jovens e adultos para o mercado de trabalho de forma racionalmente técnica se torna, a partir de uma lei, um lócus de formação de professores, que exige uma formação diametralmente oposta, ou seja, racionalmente reflexiva.

Assim, é preciso ter um olhar atencioso para todas as características que permeiam o cotidiano dos IF e, de forma singular, como a formação de professores está acontecendo nesse novo ambiente de formação, haja vista que historicamente as universidades têm sido o lócus privilegiado de formação de professores.

Desenvolver uma pesquisa dentro do campo de formação de professores é fortalecer esse campo de pesquisa, garantindo-lhe status de autonomia, contribuindo com seu reconhecimento social. Com o crescente interesse dos pesquisadores pelas questões relacionadas à formação e ao trabalho docente, interesse esse que se expressa no aumento da produção científica sobre o tema, na visibilidade adquirida pela temática na mídia, pelo recente surgimento de eventos e publicações especificamente dedicadas às questões de formação docente, segundo André (2010, p. 174) "torna-se cada vez mais premente nos atualizarmos sobre como vem se configurando esse campo de estudos".

\section{A FORMAÇÃO DE PROFESSORES NOS INSTITUTOS FEDERAIS}

Na metade da primeira década do século XXI, mesmo já tendo passado 15 anos da Conferência de Jomtien', e 10 anos da Lei de Diretrizes e Bases da Educação Nacional - LDB ${ }^{\text {ii }}$, o Brasil ainda apresentava escassez de professores para a Educação Básica. As ações movidas na década de 1990, no período do governo de Fernando Henrique Cardoso - FHC, na direção da formação de professores fracassam e com isso o governo seguinte, de Luís Inácio Lula da Silva - Lula, a partir de 2003, precisa "correr atrás do prejuízo", temendo um "apagão" de professores da educação básica nos anos seguintes.

A Década da Educação iniciada em 1997 (instituída pela LDB) fracassa. Inúmeros são os professores da educação básica sem formação específica, e em muitos casos sem formação superior alguma nos primeiros anos do século XXI. O governo federal então elabora e propõe o Plano de Desenvolvimento da Educação - PDE, Decreto n. 6.094, lançado pelo Ministério da 


\section{O ESTADO DO CONHECIMENTO SOBRE A FORMAÇÃO DE PROFESSORES DE MATEMÁTICA NOS INSTITUTOS FEDERAIS}

Educação em abril de 2007(BRASIL, 2007a). Um Plano de Metas coletivo intitulado "Todos pela Educação" o qual objetivou melhorar a qualidade da educação no Brasil, com prioridade na educação básica. Assim, a expansão do ensino superior veio como meio de se oferecer formação inicial de nível superior aos professores. As principais questões apresentadas pelo PDE foram a formação de professores e a valorização dos profissionais da educação. Esse Plano envolvia decisões políticas e ações técnicas, visando o atendimento da demanda educacional e a melhoria dos indicadores educacionais.

Nesse período, em 2007, foi publicado um relatório produzido pela Câmara de Educação Básica do Conselho Nacional de Educação, intitulado "Escassez de professores no Ensino Médio: Propostas estruturais e emergenciais" (BRASIL, 2007b), citado anteriormente. Este relatório, fruto de estudos iniciados dois anos antes por uma comissão instituída, apresenta medidas que visavam superar o déficit docente no Ensino Médio, particularmente nas disciplinas de Química, Física, Matemática e Biologia.

$\mathrm{Na}$ direção de evitar esse colapso na educação básica nacional, vários foram os

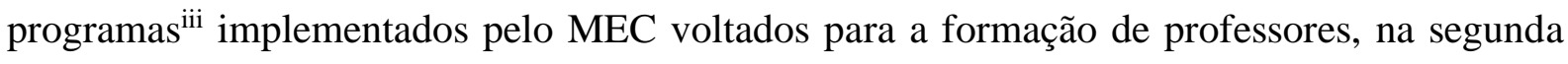
metade da década de 2000, dentre eles podemos destacar: o Programa Universidade Aberta do Brasil - UAB (2006); o Programa de Consolidação das Licenciaturas - Prodocência (2006);o Programa de Formação Continuada de Professores na Educação Especial (2007), no âmbito da UAB; o Programa Institucional de Bolsa de Iniciação à Docência - PIBID (2007); o Programa de Apoio a Planos de Reestruturação e Expansão das Universidades Federais - REUNI ${ }^{\text {iv }}$ (2007); a criação dos Institutos Federais com a determinação de $20 \%$ das vagas para Licenciaturas (2008); o Plano Nacional de Formação de Professores da Educação Básica - PARFOR (2009); O Programa Novos Talentos (2010); dentre outros. Ao longo de toda a história da educação no Brasil se percebe uma grande quantidade de programas de governo ao invés de políticas públicas. Os programas são intermitentes, momentâneos, de caráter emergencial, já as políticas são perenes e podem ser questionadas quando não cumpridas.

Nesse contexto de expansão de vagas para a formação docente a partir do Plano de Metas do PDE, é que foram criados os Institutos Federais de Educação, Ciência e Tecnologia (IFs), através da Lei $\mathrm{n}^{\circ}$ 11.892/2008. A prioridade na oferta de Licenciaturas é para cursos de Ciências e Matemática, o que vai de encontro com o texto do Relatório do CNE de 2007 (BRASIL, 2007b), que determina prioridade na abertura de cursos de formação de professores nas áreas de Química, Física, Matemática e Biologia. Essa criação se deu, entre outros motivos, 


\section{O ESTADO DO CONHECIMENTO SOBRE A FORMAÇÃO DE PROFESSORES DE MATEMÁTICA NOS INSTITUTOS FEDERAIS}

para "frear" a vontade dos demais CEFETs de se tornarem universidade ${ }^{v}$. Esses CEFETs passariam a ter autonomia equiparada às universidades, porém teriam que ofertar no mínimo $20 \%$ de suas vagas em cursos de formação de professores. Percebe-se daí como se deu a entrada das Licenciaturas nos IFs, não como uma política de Estado, um projeto pensado e discutido com toda a sociedade. Foi uma política de Governo, o mercado precisava de mais professores, imediatamente, professores formados sob o perfil de competências preconizado nas Diretrizes Curriculares Nacionais - DCN, de acordo com o CNE. O governo federal fez apenas unir as vontades, "frear" os CEFETs na marcha rumo à universidade tecnológica e obrigá-los a ofertar Licenciaturas ao mesmo tempo.

Os programas implementados pelo MEC como alternativa ao fracasso da Década da Educação, aliados à expansão desordenada de cursos de formação de professores nas IES Privadas, vem reforçar o direcionamento da formação de professores para uma lógica mercantilista, voltada para aumentar quantitativamente o quadro de profissionais, camuflada pelos discursos da erradicação do analfabetismo, preparar trabalhadores para o mercado, formar cidadãos, etc.

As Licenciaturas são, portanto, fixadas nos IFs como uma política de Governo que visava atender a uma necessidade emergencial de suprir professores para a Educação Básica. Tal qual em toda a história da Educação Profissional no Brasil, que sempre se preocupou com as necessidades emergenciais de formação de trabalhadores, agora os IFs assumem o mesmo papel. Necessidades emergenciais para formação de professores são comuns na história da educação do Brasil, haja vista os Esquemas I e II ${ }^{\mathrm{vi}}$, criados emergencialmente na década de 1970.

Os CEFETs já ofertavam cursos de formação de professores no início dos anos 2000, a partir do Decreto 3462/2000 vii (BRASIL, 2000), porém de forma descompromissada com a qualidade não considerando o aspecto pedagógico da formação docente (AZEVEDO, 2017). A oferta de Licenciaturas era pequena por falta de interesse e expertise nesse tipo de formação. Além disso a oferta de cursos técnicos integrados estava proibida, por Decreto, a partir de 1997, no governo FHC, o que fez com que os CEFETs investissem em Cursos Superiores de Tecnologia e Bacharelados, a exemplo da CEFET-PR. Em 2004, já no governo Lula, os cursos técnicos integrados são (re) implantados, porém o "estrago" foi grande e os CEFETs já não queriam mais retroceder, pois já vislumbravam a futura Universidade Tecnológica, a exemplo do CEFET-PR que "evoluiu” para a UTFPR em 2005. Outros CEFETs intentavam o mesmo 


\section{O ESTADO DO CONHECIMENTO SOBRE A FORMAÇÃO DE PROFESSORES DE MATEMÁTICA NOS INSTITUTOS FEDERAIS}

feito, principalmente os CEFETs do Rio de Janeiro e de Minas Gerais. A criação dos IFs pode ser entendida como uma forma de "frear" esse sonho universitário dos CEFETs, como já mencionado anteriormente.

As Licenciaturas ofertadas nos CEFETs, no início dos anos 2000, fracassaram tanto no modelo como no número de cursos, pois nunca foi interesse dos CEFETs ofertar esse tipo de curso, por isso não houve esforço. Mesmo o Decreto 3462/2000 autorizando os CEFETs a criarem cursos de formação de professores, não houve a preocupação do Estado em formar um quadro de professores específico para as licenciaturas e para os programas de complementação pedagógica desconsiderando o aspecto pedagógico da formação docente com baixo investimento em laboratórios e bibliotecas específicas, como constatado na pesquisa de Azevedo (2017). A experiência frustrada de formar docentes nos CEFETs pode ser considerada, desta forma, um prelúdio na história da origem das licenciaturas nos IFs. As Licenciaturas não foram incorporadas aos CEFETs, foram inseridas como um apêndice. Estudos como o de Azevedo (2017) mostram que uma das razões pela preferência de Licenciaturas em Ciências e Matemática nos IFs é o fato de já ter número considerável de professores nessas áreas, dado que os CEFETs eram voltados exclusivamente para formação tecnológica. Não é surpresa, portanto, que o curso de Licenciatura em Química é o que se apresenta no maior número de IFs dada sua especificidade. ${ }^{\text {viii }}$

Com a nova institucionalidade os CEFETs se veem na obrigação de se tornar necessariamente um lócus de formação de professores, visto que a Lei que cria os IFs (BRASIL, 2008) determina que $20 \%$ das vagas sejam ofertadas em cursos de formação de professores. O descaso dos CEFETs com a formação de professores acabou sendo transplantado para os IFs.

Os IFs já nascem como autarquia, detentoras de autonomia administrativa, patrimonial, financeira, didático-pedagógica e disciplinar (Art. $1^{\text {o }}$, Parágrafo Único) e também autonomia para criar e extinguir cursos, nos limites de sua área de atuação territorial (Art. $2^{\circ}, \S 3^{\circ}$ ). Essa autonomia, porém, é colocada à prova já de início, pois os IFs devem escolher as Licenciaturas que serão ofertadas dentro de um limite de prioridades estabelecido - Ciências da Natureza e Matemática - e também devem se submeter, de maneira vertical, a uma mudança brusca de rumo nas instituições que, por vocação e tradição, têm todo um trabalho voltado para a educação profissional.

A escolha destes cursos dentro do limite das áreas estabelecidas não seguiu, necessariamente, critérios claros. Arruda e Paula (2012) apontam que a escolha do curso a ser Revista RBBA $\mid$ Revista Binacional Brasil Argentina 


\section{O ESTADO DO CONHECIMENTO SOBRE A FORMAÇÃO DE PROFESSORES DE MATEMÁTICA NOS INSTITUTOS FEDERAIS}

implantado não partiu, necessariamente, da demanda da região ou da afinidade tradicional da instituição.

Outro fator que levanta dúvida em relação ao compromisso com os cursos de formação de professores é a seleção dos docentes. Os concursos para docentes nos IFs não são específicos para atuar em um determinado curso - nas licenciaturas, por exemplo. Com isso, mesmo que haja a necessidade de professores específicos para determinada disciplina de um curso de Licenciatura o concurso para docentes que atuarão nas licenciaturas não necessariamente exigirá que os profissionais sejam licenciados ou tenham experiência docente anterior. Opta-se por valorizar a titulação e uma formação que permita a regência em vários cursos e disciplinas. Esse mecanismo induz ao movimento de flexibilização e polivalência da prática docente o qual ameaça a qualidade da formação dos futuros professores e outros profissionais. Da mesma forma há uma intensificação do trabalho que privilegia a atuação polivalente do professor e não seu direcionamento para a pesquisa, impedindo a criação de um ambiente favorável à produção e disseminação do conhecimento e à indissociabilidade entre ensino, pesquisa e extensão.

Arruda e Paula (2012) questionam se a política que determinou a formação de professores nos IF também não estaria implementando um novo perfil funcional docente, que se caracterizaria não só por uma política de elevação da titulação, mas pela demanda de uma "prática docente polivalente" (p. 10), onde o professor é exposto a situações complexas, que requerem maior atuação cognitiva, diferentemente do docente multifuncional, que é submetido a um maior número de tarefas em adição às que realiza, sem que com isso ocorra maior intelectualização do trabalho. As autoras ainda lembram que a política de expansão das universidades federais - REUNI do mesmo modo privilegiou cursos de licenciatura, não necessariamente por compreenderem a importância da formação de professores como tarefa da universidade, mas por serem cursos considerados 'mais baratos' pois requerem menor investimento.

Nesse sentido, Arruda e Paula (2012) concluem que

identifica-se o risco de que a política de formação de professores nos IFs esteja mais associada a formação de uma reserva de docentes para suprir a carência destes no ensino médio, do que a um projeto de elevação da qualidade do ensino e de criação de condições efetivas para o estabelecimento de uma proposta educacional que vise o domínio e a produção de conhecimento tecnológico e a superação de assimetrias internas e externas. (p. 11). 


\section{O ESTADO DO CONHECIMENTO SOBRE A FORMAÇÃO DE PROFESSORES DE MATEMÁTICA NOS INSTITUTOS FEDERAIS}

Sobre esse ponto de vista de Arruda e Paula (2012) se percebe que as autoras aceitam como verdade a escassez de professores e partem daí para concluir que a formação de professores nos IFs surge no cenário educacional para suprir essa carência e não como um projeto de elevação da qualidade do ensino. Como veremos adiante, todas as pesquisas analisadas que investigaram cursos de formação de professores de Matemática nos IFs partem do mesmo ponto. O diferencial desta pesquisa de Arruda e Paula (2012) é que estas autoras levantam um outro ponto de discussão: estas Licenciaturas nos IFs não cumprem nem o anseio por essa elevação da qualidade, visto que os cursos não diferem dos universitários e também não cumprem o anseio da carência de professores, visto que o número de concluintes é muito baixo $^{\text {ix }}$, assim como a eficiência acadêmica.

A trajetória dos cursos de formação de professores nos IFs se inicia então repleta de questionamentos sobre os reais motivos de sua concepção no interior dos IFs, uma instituição fundada sob os pilares da racionalidade técnica, com pouca ou nenhuma expertise na oferta de cursos de formação de professores. Trata-se de um modelo institucional com características peculiares como a verticalização do ensino, que permite uma interlocução direta da Educação Básica com o Ensino superior, a realização de percursos formativos dentro de uma mesma instituição (desde a Educação Básica até a Pós-Graduação) e a proposta da formação baseada no tripé ensino, pesquisa e extensão.

Quando tratamos de formação de professores no âmbito da Educação Profissional temos que levar em conta o viés da politecnia, que concebe o indivíduo em sua totalidade, ou seja, um processo de formação amplo, contrário ao modelo de capacitação cujo objetivo seja formar o professor adaptado ao mercado de trabalho. Longe disso, a formação de professores nos Institutos Federais deve ser promovida sob a égide da indissociabilidade entre a base teórica e sua atividade prática. Assim, o objetivo da formação não deve se sintetizar apenas em capacitar o professor, como muitos programas e políticas costumam objetivar, mas procurar uma valorização da docência, a partir do seu profissional, tendo como pressuposto que esse processo formativo é um continuum (REIS, 2017, p. 42), que se faz e se refazem todos os momentos da vida profissional do professor, a qual não pode ser pensada de forma apartada da vida pessoal e social desse mesmo indivíduo.

O fato do IFs/CEFETs tem suas origens pautadas no modelo da racionalidade técnica nos faz concordar com Ciavatta (2006) quando esta pesquisadora discorda que os cursos de licenciaturas nos IF estejam alinhados ao mercado de trabalho. Apesar da autora analisar a

Revista RBBA Revista Binacional Brasil Argentina 


\title{
O ESTADO DO CONHECIMENTO SOBRE A FORMAÇÃO DE PROFESSORES DE MATEMÁTICA NOS INSTITUTOS FEDERAIS
}

formação de professores ofertada nos CEFETs, as mesmas análises podem ainda ser feitas com relação aos cursos ofertados pelos IF. Consoante a autora,

\begin{abstract}
se a formação oferecida pelos CEFETs se pautar pela oferta de cursos breves, pela redução da formação às questões tecnológicas demandadas pelo mercado, pela lógica do mercado, esses professores estarão sendo lesados -mesmo que com seu consentimento - no direito a uma formação condizente com a lógica da educação e da humanização daqueles jovens e adultos que lhes serão confiados (CIAVATTA, 2006. p. 929).
\end{abstract}

Em estudo recente, Lima (2014) apresenta preocupação com a transformação dos IF em lócus de formação de professores apenas pelo fato de carência de professores especializados para determinadas áreas do ensino. Para a autora, "consolidar uma instituição especializada em educação profissional como formadora de professores apenas pela necessidade quantitativa de docentes torna vazia esta proposição política” (LIMA, 2014, p. 14).

É inevitável considerar que os Institutos Federais, no sentido de se colocar enquanto lócus de formação de professores devidos as suas características, isto é, de formação de técnicos e tecnólogos, quando se trata de formação de professores, não podem ser comparados às universidades, lócus privilegiado para este fim, pois

os Institutos Federais constituem uma organização de ensino com certas particularidades: possuem um histórico específico relacionado a educação profissional; têm uma variedade de níveis de cursos ofertados; e realizam seu vínculo com o Ministério da Educação (MEC) por meio da Secretaria de Educação Profissional e Tecnológica (SETEC), que traz para os IF uma missão com a profissionalização do país em seu aspecto técnico e tecnológico (LIMA, 2014, p. 14).

Os Institutos Federais, por outro lado, de acordo com Flores e Lamb (2013, apud REIS, 2017), por trabalharem com modalidades de ensino variadas, podem se tornar ambientes profícuos para formação de professores, pois os professores formadores teriam a acesso a condições de trabalho diferenciadas dos formadores que trabalham em instituições universitárias, justamente por transitar nas diversas modalidades. Esses autores afirmam que,

os Institutos Federais tornam-se um lócus privilegiado devido a sua capilaridade enquanto rede de educação profissional e consequente abrangência regional, mas principalmente porque atua com Educação de 


\section{O ESTADO DO CONHECIMENTO SOBRE A FORMAÇÃO DE PROFESSORES DE MATEMÁTICA NOS INSTITUTOS FEDERAIS}

Jovens e Adultos no programa chamado PROEJA -Programa de Integração da Educação Profissional com a Educação de Jovens e Adultos. E por atuar no ensino técnico, que vem ultimamente discutindo a implantação de um currículo integrado da formação geral com a formação profissional, apresentase como um espaço propício a trabalhar com esta perspectiva na formação de professores, até porque na maioria dos casos, os professores que atuam nos cursos de licenciaturas, são os mesmos que atuam nos curso PROEJA e no Ensino Médio Integrado (FLORES; LAMB, 2013, p. 4, apud REIS, 2017, p. 174).

Outra questão que ainda diz respeito a formação de professores nos IF, segundo Lima (2014, p. 74), é o fato da diversificação dos locais que ofertam formação de professores, indo na contramão da criação de uma "base comum nacional" (FREITAS, 1999, p. 30), resultado em fragmentação para esse professor formativo:

Ainda com relação à formação de professores nos IF,

ao diversificar a formação de professores, por levá-la para instituições que possuem uma tradicional oferta de cursos técnicos, ocorre uma fragmentação da formação de professores. Esta fragmentação ocorre, principalmente, pois a diversificação de lócus não se articula à criação de um sistema nacional de formação de professores, ou mesmo, a uma base comum nacional (LIMA, 2014, p. 74).

Ainda na linha de pensamento a respeito da diversidade de lócus de formação de professores, Silva (2006, apud REIS, 2017) aponta outra fragilidade que pode decorrer dessa diversidade. A autora

adverte quanto ao fato de que a diversificação de instituições formadoras leva à multiplicidade de modelos de formação seja no que tange aos tipos de cursos, aos currículos, à carga horária e, principalmente, ao perfil do profissional da educação (SILVA, 2006, p. 67, apud REIS, 2017, p. 175).

Os IFs, com a grande diversidade na oferta de educação profissional e tecnológica, acabaram abarcando uma variedade de níveis e modalidades de educação, que não foi devidamente acompanhada de uma política ou políticas de formação de professores, permanecendo o insistente histórico de "fragmentação, improviso e insuficiência de formação pedagógica na prática de muitos professores que trabalham nos IF” (REIS, 2017). A maior preocupação com essa formação então, é a de entender como uma instituição historicamente racional técnica pode formar professores, pois consideramos que a formação de professores deveria se distanciar de tal característica, como já afirmamos. 


\section{O ESTADO DO CONHECIMENTO SOBRE A FORMAÇÃO DE PROFESSORES DE MATEMÁTICA NOS INSTITUTOS FEDERAIS}

Entretanto, cabe salientar também, que a formação de professores nos Institutos, na forma como hoje está organizada, ainda é um fato muito recente e requer muitos outros estudos. Em princípio, porém, podemos inferir, corroborando com Lima (2014), que a formação de professores nos IF pelo,

seu indicativo histórico, de formação técnica, pode incidir que a formação será realizada de forma tecnicista e pragmática, cujo viés caracteriza o ensino profissional. No entanto, os diferentes níveis de ensino em mesmo local, oferecidos pelos IF, permite uma aproximação do mundo do trabalho, por exercer a formação de professores da educação básica em mesmo lócus onde ocorre a prática profissional do professor de educação básica (LIMA, 2014, p. 66).

A indissociabilidade entre ensino, pesquisa e extensão, nos mesmos moldes das instituições universitárias que faz dos IF locais muito próximos das universidades e, mais privilegiados ainda, por terem dentro do mesmo espaço, a educação básica, a qual, geralmente, fica distante do espaço universitário e consequentemente dos futuros professores formados naquele espaço. Por outro lado, vale salientar que apesar dos IF apresentarem o tripé ensinopesquisa-extensão, em se tratando da pesquisa, apenas as pesquisas aplicadas são estimuladas e preconizadas na Lei $\mathrm{n}^{\mathrm{o}} 11.892 / 2008$ : “Os Institutos Federais por serem instituições de administração pública, de oferta gratuita, porém, do âmbito do tripé ensino, pesquisa e extensão, a pesquisa estimulada a ser realizada é a pesquisa aplicada" (LIMA, 2014, p. 70-grifo nosso).

A pesquisa aplicada, por sua conceituação, se aproxima da pesquisa imediatista de aplicabilidade quase instantânea e com resultados lucrativos, cujo objetivo é resolver um problema prático. Essa conceituação pode ser entendida quando são apresentados os objetivos dos IF, no art. $7^{\circ}$, III, da Lei que os criou: "III - realizar pesquisas aplicadas, estimulando o desenvolvimento de soluções técnicas e tecnológicas, estendendo seus benefícios à comunidade" (BRASIL, 2008).

Entendemos, portanto, que esse tipo de pesquisa está alinhado com o pensamento neoliberal e, poderia ser aplicado nos IF enquanto formador de técnico, tecnólogo e bacharel, além de obviamente, estar em consonância com os pressupostos da racionalidade técnica. Por isso, reiteramos que esse tipo de pesquisa não se aplica a formação de professores, pois nessa formação a pesquisa deve ser vista como parte da docência, mas um outro tipo de pesquisa, uma que não se resuma em apenas criar bens de consumo visando o aumento de lucro. Esse contexto nos faz concordar com Moura (2007), ao explicitar que: 


\section{O ESTADO DO CONHECIMENTO SOBRE A FORMAÇÃO DE PROFESSORES DE

o professor precisa ser formado na perspectiva de que a pesquisa e o desenvolvimento tecnológico devem estar voltados para a produção de bens e serviços que tenham capacidade de melhorar as condições de vida dos coletivos sociais e não apenas produzir bens de consumo para fortalecer o mercado e, em consequência, concentrar a riqueza e aumentar o fosso entre incluídos e os excluídos (MOURA, 2007, p. 18).

Nesse sentido, defende-se a tese de que os IFs, com esta estrutura verticalizada de ensino, aliada à tríade ensino, pesquisa e extensão, podem ser um meio profícuo para a formação dos docentes, desde de que sejam concebidas e planejadas ações estratégicas que considerem as características das suas licenciaturas e do seu contexto institucional, indicando uma quebra do paradigma da racionalidade técnica. Caso contrário, esse novo lócus de formação apenas reproduzirá a formação ainda tecnicista proveniente das Universidades. Essa afirmação se baseia em alguns fatos como: os Projetos Pedagógicos desses novos Cursos - PPC não foram elaborados a partir das peculiaridades dos IFs, visto que a Lei já estava em vigor e não se teve o tempo hábil para tal elaboração, além do fato da ainda inexistente identidade institucional que caracterizasse os cursos da REDE; outro fato, como já mencionado, foi a falta de expertise dos gestores dos IFs com cursos de formação de professores, somada ao fato dos professores recém contratados serem oriundos de cursos de pós-graduação das Universidades, daí a impregnação da cultura universitária nos PPCs dos cursos de formação de professores da REDE desde o início da oferta. Mesmo buscando uma identidade que se dissocie da Universidade, os cursos de formação de professores da REDE têm um pé fincado na Universidade. Por esse motivo foi fundamental conhecer o contexto histórico da implantação tardia do modelo universitário no Brasil e consequentemente dos cursos de formação de professores.

Outra questão que emerge desta discussão a respeito, por um lado do novo lócus de formação e por outro lado da necessidade de formação de profissionais da educação que sejam críticos e reflexivos, é a possibilidade de juntar estes dois pontos, ou seja, se é possível formar professores reflexivos, sob um viés de politecnia que concebe o indivíduo em sua totalidade, em um ambiente tradicionalmente racional técnico sob o risco de simplesmente formar o professor adaptado ao mercado de trabalho, tal qual se pretende formar o egresso desse lócus de ensino.

São muitos aspectos conflitantes que permeiam a formação de professores na REDE. Assim como na formação dos alunos dos cursos técnicos também a formação de professores na 


\section{O ESTADO DO CONHECIMENTO SOBRE A FORMAÇÃO DE PROFESSORES DE MATEMÁTICA NOS INSTITUTOS FEDERAIS}

Educação Profissional sofre com a falta de comprometimento por parte dos órgãos responsáveis pela educação brasileira em viabilizar meios e recursos para que esse processo formativo assuma características de formação de qualidade e faça com que ela deixe de ser concebida como apêndice da política educacional. A formação de professores deve ser concebida como política de Estado e não de governo (temporária) sob risco de uma concepção restrita da prática, levando a uma formação de professor como um aplicador de teorias, isto é, apenas um técnico e não um profissional com domínio sobre sua prática, com autonomia e capacidade para construir conhecimentos pedagógicos e para a tomada de decisões. O professor deve ser concebido como um pesquisador crítico em direção a uma educação emancipatória.

Consideramos a reflexão como parte da docência, a reflexão na e sobre a prática, e a educação como processo. Nesse contexto, vários estudos e pesquisadores na área de educação apontam para a importância de se pensar e/ou repensar o processo de formação de professores, considerando a quebra dos paradigmas que norteiam esse processo formativo. Por isso, para garantir a qualidade dos cursos de formação de professores da REDE, como profissionais da educação, se faz necessária essa mudança brusca de paradigma, da racionalidade técnica para a racionalidade crítica.

Nos dez anos seguintes à promulgação da Lei 11892/2008 que criou os IFs a significativa expansão dessas instituições transformou a vida de milhões de jovens e adultos, principalmente da classe trabalhadora que conseguiu ingressar na educação profissional e superior. Em 2018 a REDE já contava com $647^{x}$ campi que funcionam em 568 municípios brasileiros, com mais de um milhão de estudantes matriculados e cerca de 80 mil servidores entre professores e técnico-administrativos.

Ao observarmos o corpo docente dos IFs mais de $80 \%$ são mestres ou doutores de acordo com a Plataforma Nilo Peçanha - PNP. Trata-se de um efetivo altamente titulado que vem desenhando uma nova história às antigas Escolas Técnicas/Agrotécnicas Federais ETFs/EAFs e CEFETs. Estes novos docentes recém-formados nos programas de pós-graduação das Universidades trazem um academicismo perigoso aos IFs sob o ponto de vista dos professores mais antigos, em sua maioria ex-alunos das ETF/EAF. Para esses antigos, os novatos trazem para os IFs a cultura da Pesquisa, sem o conhecimento técnico necessário para a boa formação das próximas gerações de técnicos, colocando em risco o futuro do ensino técnico no país. Passados esses 10 anos, ainda vemos, sobretudo nos IFs mais antigos, essa 


\section{O ESTADO DO CONHECIMENTO SOBRE A FORMAÇÃO DE PROFESSORES DE MATEMÁTICA NOS INSTITUTOS FEDERAIS}

rivalidade entre novatos (recém contratados) e nativos (funcionários antigos, que são em grande parte ex-alunos das ETFs/EAFs).

A principal estratégia adotada pelos IFs para disseminar e desburocratizar o acesso à educação técnica e tecnológica para diversos locais do país foi apostar em campi descentralizados e com autonomia financeira para atender às particularidades de cada região de forma singular, conforme afirmam Turmena e Azevedo (2017). O objetivo era que pessoas que não poderiam se deslocar de sua região para estudar nas cidades grandes fossem contempladas com instituições mais próximas ou até mesmo em seu município. A interiorização dos Institutos Federais representou na prática a inclusão, a partir do acesso, de milhares de pessoas que antes estavam apenas à margem. Há um esforço do Estado em ampliar a oferta de matrículas e interiorizar a educação federal, com a criação dos IFs e ampliação dos campi em estados até então excluídos de efetivas políticas públicas em educação profissional e tecnológica. $\mathrm{O}$ processo de interiorização dos IFs, associado à estrutura multicampi, foi uma conquista muito importante para a história da educação brasileira por ter promovido um avanço no ensino profissional de qualidade e também o acesso a segmentos excluídos historicamente dessa modalidade de ensino, tanto na educação profissional, quanto na superior.

Os IFs possuem uma maior inserção territorial do que as próprias universidades públicas, porque na maioria dos casos as universidades estão nas grandes cidades e nos centros urbanos. Já os IFs estão fixos em locais de pequeno e médio porte, em mais de 500 municípios brasileiros.

Em relação aos cursos de Licenciatura em Matemática, por exemplo, ofertados nos IFs, constatou-se que dos 91 cursos presenciais em atividade (em 2018), apenas 30 cursos são ofertados em um raio de $100 \mathrm{~km}$ das capitais dos estados (dos quais 16 são ofertados nas próprias capitais dos estados), os outros 61 cursos são ofertados a mais de $100 \mathrm{~km}$ de distância das capitais dos estados, existem cursos ofertados presencialmente a mais de $800 \mathrm{~km} \mathrm{de}$ distância da capital do estado.

Segue abaixo um gráfico que apresenta a evolução numérica desses cursos, ao longo dos últimos anos.

Revista RBBA $\mid$ Revista Binacional Brasil Argentina 


\section{O ESTADO DO CONHECIMENTO SOBRE A FORMAÇÃO DE PROFESSORES DE

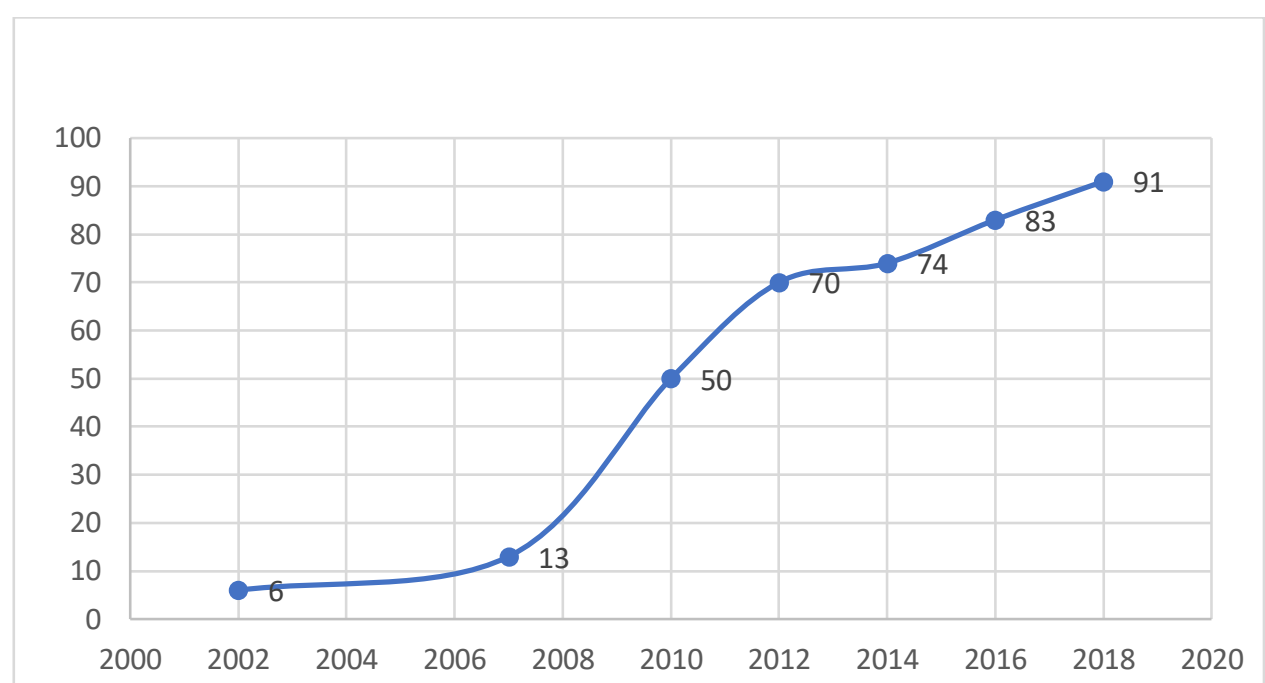

Gráfico 1 - Expansão dos Cursos de Licenciatura em Matemática nos Institutos Federais

Estes dados foram coletados diretamente dos PPCs dos cursos e/ou das páginas oficiais dos IFs. Até 2002 apenas 6 cursos de Licenciatura em Matemática eram ofertados nos CEFETs. A partir de 2003, já no governo Lula, e em decorrência do Decreto 3462/2000 que autorizava os CEFETs a ofertarem Licenciaturas e do Decreto 5225/2004 (BRASIL, 2004), que transformou os CEFETs em Instituições de Ensino Superior - IES, o número de cursos de Licenciatura em Matemática sobe para 13 até o ano de 2007, sendo mais 2 (dois) na região Sudeste e mais 5 (cinco) na região Nordeste. O ano de 2007 já foi de grande mobilização das instituições federais de Educação Profissional para se organizarem a fim de se constituir os IFs. Ao longo de 2008 várias instituições já começaram a se adequar à nova Lei que estava para ser promulgada, a partir desse ano já se observa uma corrida para a inserção de cursos de Licenciatura nos IFs, e em particular, de Matemática. Em três anos (2008 - 2010) foram 37 novos cursos implantados nas unidades dos IFs recém-criados e mais 20 novos cursos no biênio seguinte (2011 - 2012). A título de comparação, enquanto no quinquênio 2003/2007 foram criados apenas 7 cursos, ainda na institucionalidade de CEFET, no quinquênio 2008/2012 foram implantados 57 novos cursos de Licenciatura em Matemática, um aumento expressivo e assustadoramente rápido. 


\section{O ESTADO DO CONHECIMENTO SOBRE A FORMAÇÃO DE PROFESSORES DE MATEMÁTICA NOS INSTITUTOS FEDERAIS}

Distribuindo os cursos pelas 5 regiões brasileiras, temos a seguinte tabela (dados de 2018).

\begin{tabular}{|c|c|c|c|}
\hline Região & $\begin{array}{c}\text { Institutos } \\
\text { Federais }\end{array}$ & $\begin{array}{c}\text { IFs que ofertam } \\
\text { Licenciatura em Matemática }\end{array}$ & $\begin{array}{c}\text { Unidades que ofertam } \\
\text { Licenciatura em Matemática }\end{array}$ \\
\hline CO & 5 & 4 & 6 \\
\hline $\mathrm{N}$ & 7 & 7 & 34 \\
\hline $\mathrm{NE}$ & 11 & 9 & 28 \\
\hline $\mathrm{SE}$ & 9 & 3 & 13 \\
\hline $\mathrm{S}$ & 6 & 32 & $91^{\mathrm{xi}}$ \\
\hline Total & 38 & 9 & 28 \\
\hline
\end{tabular}

Tabela 1 - Distribuição dos Cursos de Licenciatura em Matemática nos Institutos Federais em 2018.

As regiões Norte e Sudeste ofertam Licenciatura em Matemática em todos os seus IFs. Apesar da região Sul ofertar esse curso em apenas metade dos seus IFs, a oferta alcança 13 unidades, um número muito superior à quantidade alcançada pela região Centro-Oeste, que não oferta esse curso em apenas um IF, garantindo a oferta em todos os demais.

O grande desafio atual dos IFs é garantir a permanência e êxito desses alunos, já que o acesso tem sido viabilizado sobretudo pelas políticas sociais. Assim como nas Universidades, também nos IFs a evasão é um grande problema a ser severamente debatido e propostas concretas devem implementadas no sentido de combatê-la.

De acordo com a PNP em 2018 a taxa média de evasão nos cursos de Licenciatura em Matemática nos IFs foi de 17\%. Apesar de alguns IFs apresentarem taxas relativamente baixas como o IFRR (2,5\%), IFMA $(5,3 \%)$ e IFAL $(5,7 \%)$, outros apresentaram taxas bastante elevadas como IFGoiano (37,2\%), IFTO (37,5\%) e IFTM $(40,7 \%)$.

Este panorama apresentado a respeito da formação de professores de Matemática nos IFs, bem como o percurso histórico-político que culminou na inserção obrigatória de Licenciaturas na REDE, já se configura como um prelúdio das pesquisas realizadas e que passo a descrever a seguir. 


\section{O ESTADO DO CONHECIMENTO SOBRE A FORMAÇÃO DE PROFESSORES DE MATEMÁTICA NOS INSTITUTOS FEDERAIS}

\section{PESQUISAS E PESQUISADORES NA FORMAÇÃO DE PROFESSORES NOS INSTITUTOS FEDERAIS}

Várias são as pesquisas que tratam da formação de professores nos IFs. Em geral todas apresentam o aligeiramento na concepção desses cursos, deixando muito claro que os IFs recém-criados passaram a ofertar esses cursos não pela necessidade de contribuir com a resolução do problema da escassez de professores na educação básica ou pelo importante papel do professor para a formação omnilateral do sujeito, mas sim pelo cumprimento de uma Lei. Daí o caminho era descobrir qual curso daria menor demanda de trabalho na implantação e de recursos, tanto de pessoal como de equipamentos e materiais.

Verdum (2015) propõe indicadores de qualidade para os cursos de formação de professores de Educação Básica do IFRS, para tanto a pesquisadora apresenta o estado do conhecimento a respeito da formação de professores nos IFs até 2013. A pesquisa foi realizada a partir do Banco de Teses e Dissertações da CAPES, Google Acadêmico e trabalhos apresentados em eventos científicos da Associação Nacional de Pós-Graduação e Pesquisa em Educação - ANPEd e no Encontro Nacional de Didática e Prática de Ensino - ENDIPE. Esses são os principais eventos científicos da área de Educação realizado no Brasil. À época foram encontrados apenas três trabalhos de mestrado que tratavam da temática Formação de Professores nos IFs no Banco de Teses e Dissertações da CAPES. Um deles é intitulado "A formação de professores nos Institutos Federais de Educação, Ciência e Tecnologia: um estudo da concepção política", de Lima (2012). Neste trabalho a pesquisadora analisa as proposições políticas para a formação docente nos IFs, focando na obrigatoriedade legislativa de oferecer $20 \%$ (vinte por cento) das suas vagas para cursos de formação de professores. Lima (2012) conclui que na formação de professores nos IFs "prevalece uma concepção pragmática", com o incentivo de uma pesquisa aplicada, voltada para os problemas do cotidiano da prática profissional; e também indica a consolidação dos IFs como lócus de formação de professores na direção de um "intelectual tradicional", que trabalha para manter a ordem do sistema capitalista atual. Não foram encontrados trabalhos sobre essa temática nos cadernos anuais das reuniões da ANPEd. Já no ENDIPE foram identificados apenas dois artigos no período considerado. Não tendo encontrado um número relevante de trabalhos nessas fontes, a ponto de construir um estado de conhecimento para uma tese, a pesquisadora fez uso do Google Acadêmico, pelo fato desta ferramenta fazer uma busca mais abrangente. Esta busca resultou 


\section{O ESTADO DO CONHECIMENTO SOBRE A FORMAÇÃO DE PROFESSORES DE MATEMÁTICA NOS INSTITUTOS FEDERAIS}

na catalogação de doze artigos e três dissertações que ainda não estavam no Banco de Teses e Dissertações da CAPES.

Estes estudos, em geral, tinham como objetivos investigar a maneira como está se dando a implantação desses cursos nos IFs, a tendência formativa e o contexto político-educacional que levou os IFs a ofertar esses cursos. Os pontos positivos elencados são a verticalização, que propicia a interlocução com a educação básica e a atuação dos docentes nos diferentes níveis de ensino, além de favorecer a execução de projetos integradores; e também o fato de ser uma proposta de formação baseada no tripé ensino, pesquisa e extensão. Muitos foram os desafios/dificuldades/aspectos negativos encontrados como: largo espectro de atuação (operação em diferentes níveis, necessidade de elaborar e articular diferentes planos pedagógicos) e envolvimento em diferentes programas; Legado da experiência histórica, voltado para uma formação técnica-instrumental; Dificuldades em articular conhecimentos específicos e conhecimentos pedagógicos, resultando numa formação "bacharelesca"; Falta de identidade das licenciaturas dentro dos IFs; Falta de corpo docente especializado em conhecimentos pedagógicos; Concepção curricular pragmática, pouca clareza quanto aos pressupostos; Currículos com desequilíbrio entre formação específica e formação pedagógica; Perfil de estudante mais trabalhador, dificultando a participação em projetos de pesquisa e extensão; Atuação tímida na formação de professores para a educação básica e Tecnológica (EBT). Por fim, estes estudos apontam como propostas: avaliar os resultados da formação dos licenciandos de maneira contínua; avaliar a estrutura dos cursos; construir uma concepção de formação docente, uma identidade para as licenciaturas, no âmbito dos IFs; refletir sobre os aspectos que envolvem uma formação de professores com qualidade; identificar as semelhanças na formação de professores nos IFs e nas universidades; qualificar a formação dos formadores; conhecer o perfil do estudante; levantamento da demanda, de forma aprofundada, para ofertar os cursos de licenciatura.

As pesquisas até então, em sua maioria, destacaram de sobremaneira os aspectos negativos, sobretudo no tocante à tradição técnica e ao receio de essas instituições contribuírem somente para o aumento de vagas, para resolver um problema emergencial, o que coloca em dúvida as condições dos IFs em ofertar Licenciaturas para a educação básica. Porém há alguns aspectos positivos, que podem gerar propostas pedagógicas inovadoras, como a verticalização do ensino, aliada ao tripé ensino, pesquisa e extensão. 


\section{O ESTADO DO CONHECIMENTO SOBRE A FORMAÇÃO DE PROFESSORES DE MATEMÁTICA NOS INSTITUTOS FEDERAIS}

De lá para cá inúmeras pesquisas foram desenvolvidas nos programas de pós-graduação no Brasil com a temática da formação de professores nos IFs. Pesquisas estas que investigam o perfil dos estudantes que ingressam nesses cursos e também dos egressos; investigam o currículo; investigam o perfil dos formadores; investigam os motivos da evasão; e principalmente, investigam como se desenvolveu o processo de implantação desses cursos nos IFs. Todos esses trabalhos, de mestrado e doutorado, obtidos no Banco de Teses e Dissertações da CAPES, nos auxiliam em um novo estado do conhecimento desta temática. O estado do conhecimento se diferencia do estado arte, enquanto o primeiro se trata de um recorte, delimitando as publicações qualificadas analisadas e o período de tempo analisado, onde se constrói um panorama do conhecimento daquela temática a partir do que já foi elaborado, destacando enfoques e identificando lacunas, o segundo é muito abrangente, utiliza um espaço de tempo ampliado e expande as fontes de pesquisa (ROMANOWSKI; ENS, 2006, apud VERDUM, 2015).

O aumento na produção científica se deve ao aumento considerável no número de cursos de Licenciatura que foram implantados devido a exigência legal, acarretando aumento no número de alunos e consequentemente de professores, o que tornou esses cursos em férteis lócus de pesquisa.

Para Oliveira e Burnier (2013, apud REIS, 2017) a formação de professores nos IF apresenta-se como um amplo campo de estudos, principalmente, devido as especificidades que perpassam esse processo formativo, se considerado as características do lócus onde está sendo ofertada:

as licenciaturas nos institutos situam-se num âmbito amplo de formação de professores, importante de ser conhecido para tratamento mais fecundo dessas licenciaturas. Esse contexto envolve, entre outras características, as da atual rede federal de educação profissional, científica e tecnológica, da qual os institutos fazem parte, as dos próprios institutos, particularmente considerados, e as do campo de formação de professores (OLIVEIRA; BURNIER, 2013, p. 145, apud REIS, 2017, p. 158).

A seguir a Tabela 2 apresenta os números de dissertações e teses produzidas a partir de 2013 que discutem a temática "Licenciaturas nos IFs", extraídas do Banco de Teses e Dissertações da CAPES. Foram utilizadas combinações dos termos: IF(s), Instituto(s) Federal(ais), Educação Tecnológica, Formação de professores, Licenciatura(s), Rede Federal, Educação Básica. A pesquisa resultou em centenas de resultados, porém muitos foram 


\section{O ESTADO DO CONHECIMENTO SOBRE A FORMAÇÃO DE PROFESSORES DE MATEMÁTICA NOS INSTITUTOS FEDERAIS}

descartados por não estarem diretamente relacionados à temática. Dado o número expressivo de dados não foi feita busca em outros bancos de dados, como na pesquisa de Verdum (2015).

\begin{tabular}{|l|l|l|l|l|l|l|l|l|}
\hline & 2013 & 2014 & 2015 & 2016 & 2017 & 2018 & 2019 & Total \\
\hline Dissertações & 8 & 6 & 9 & 9 & 9 & 6 & 2 & 49 \\
\hline Teses & 2 & 2 & 2 & 7 & 6 & 4 & 2 & 25 \\
\hline Total & 10 & 8 & 11 & 16 & 15 & 10 & 4 & 74 \\
\hline
\end{tabular}

Tabela 2 - Dissertações e Teses produzidas no Brasil sobre as Licenciaturas nos IFs.

Estes trabalhos apresentam temas variados, porém grande parte diz respeito ao desenvolvimento do processo de implantação dos cursos de Licenciatura. Estas pesquisas analisam a implantação de um curso de Licenciatura específico ou de um conjunto de cursos de Licenciaturas dentro de um mesmo campus, ou dentro de um IF, ou entre IFs. Dentre eles podemos citar o importante trabalho de Flach (2014) que teve como propósito compreender como estava ocorrendo o processo de consolidação dos cursos de licenciatura nos IFs a partir da experiência desenvolvida no IFRS. A pesquisadora afirma que a abertura de cursos desta modalidade representa uma novidade para muitas destas novas instituições, que não possuem experiências consolidadas neste cenário de cursos.

Outro importante estudo foi realizado recentemente por Silva (2017). A pesquisa teve como objetivo compreender o processo histórico-político-social de incorporação das licenciaturas à nova política de Educação Profissional e Tecnológica, procurando revelar as concepções presentes no projeto de Educação Profissional, na modalidade pública federal, especificamente relacionada às licenciaturas ofertadas nos IF. O que se questionou é por que, no processo histórico de diversificação de modalidades e formatos de Educação Profissional Tecnológica no Brasil, os cursos de licenciaturas foram ofertados no campo da Educação Profissional, ou seja, por que o projeto de reformulação da Educação Profissional e Tecnológica engloba as licenciaturas? Qual o propósito e as finalidades da Política de Formação de professores na EPT? Os cursos de licenciatura ofertados pelos IF pretendem formar para a Educação Básica ou para a Educação Profissional? 


\section{O ESTADO DO CONHECIMENTO SOBRE A FORMAÇÃO DE PROFESSORES DE MATEMÁTICA NOS INSTITUTOS FEDERAIS}

Considerável também é o número de trabalhos que dizem respeito aos números da evasão. Das 49 dissertações nesse período, 8 dizem respeito a este tema. O tema da evasão no contexto das Licenciaturas nos IFs, em particular de Matemática, se tornou recorrente a partir da "transição de uma educação de elite para uma educação de massas"(ANTUNES SANTANA, 2016, p. 311) e são constantemente discutidas pelo fato da evasão, segundo o MEC, ser um indicativo de falhas no processo de ensino e ineficácia do serviço prestado, além de um aumento nos gastos financeiros, pois a mesma estrutura acadêmica que deveria atender determinado grupo inicial estaria sendo destinada a um quantitativo menor de alunos. Moraes e Theóphilo (2005, p. 5 apud Gonçalves, 2018, p. 33) entendem que "a evasão escolar é um dos maiores e mais preocupantes desafios do Sistema Educacional, pois é fator de desequilíbrio, desarmonia e desajustes dos objetivos educacionais pretendidos".

Todas estas pesquisas, tanto as que foram elencadas por Verdum (2015) como as que foram desenvolvidas posteriormente, trazem em comum dois elementos muito importantes e que merecem destaque. O primeiro elemento diz respeito à Carta de Natal. Parece que os pontos positivos e negativos da implantação das Licenciaturas nos IFs são repetições do que já havia sido observado quando da escrita desta Carta, em 2010. Esta Carta ${ }^{\mathrm{xii}}$, importante documento norteador para a implantação das Licenciaturas nos IFs, foi deixada de lado, foi esquecida, tanto que nenhum dos 91 PPCs de Licenciatura em Matemática dos IFs citam esta carta. Concomitante a isso todos esses PPCs tem como justificativa para a implantação do curso a escassez de professores de Matemática, seja a nível local ou regional. Esse fato é corroborado pelas pesquisas analisadas, sendo este o segundo elemento a ser destacado no contexto de nossa pesquisa. Estas pesquisas não contrariam o discurso da escassez de professores, todas elas partem do princípio da necessidade de formar mais professores para a Educação Básica, sob o risco de um “apagão" na próxima década. Muitas, inclusive, citam o relatório do CNE de 2007 (BRASIL, 2007b). Os variados temas abordados por estas pesquisas em resumo se limitam a elencar as mazelas do campo da formação de professores partindo principalmente das políticas públicas existentes e concluem que a escassez de professores não será resolvida por problemas nessas políticas ou nos projetos dos cursos.

Nenhuma destas pesquisas questionou se, de fato, havia a necessidade da abertura daquele curso de Licenciatura no IF. Os estudos tomaram como ponto de partida a Lei e a obrigatoriedade da oferta de Licenciaturas, elas não olharam para trás. Um exemplo é a pesquisa de Bavaresco (2014), que descreveu toda a trajetória política e histórica da implantação do curso

$$
\text { Revista RBBA } \mid \text { Revista Binacional Brasil Argentina }
$$




\section{O ESTADO DO CONHECIMENTO SOBRE A FORMAÇÃO DE PROFESSORES DE MATEMÁTICA NOS INSTITUTOS FEDERAIS}

de Licenciatura em Matemática no Instituto Federal do Rio Grande do Sul - Campus Bento Gonçalves. A pesquisa, apesar de importante e muito bem fundamentada, reduz-se aos aspectos do "como" implantar em detrimento do "porque" implantar. É claro que as leis são elaboradas para serem cumpridas, porém a única justificativa da implantação se restringe ao cumprimento da Lei.

Bavaresco (2014), em sua pesquisa de doutoramento, intenta compreender como se deu a implantação do curso de Licenciatura em Matemática no campus Bento Gonçalves (BG) do Instituto Federal do Rio Grande do Sul - IFRS. O Conselho Diretor do antigo CEFET - BG teve, segundo o pesquisador, muita dificuldade em implantar um curso de licenciatura naquela instituição, principalmente pela oposição dos "nativos"xiii, que "discordava da descaracterização da tradição institucional que esse curso geraria” (p. 147). A instituição não possuía pessoal suficiente e nem estrutura pedagógica para "bancar" uma licenciatura, por outro lado,

se fosse esperar compor a estrutura necessária para iniciar o curso, não seria possível, uma vez que a estratégia adotada era de gerar a demanda para justificar perante o Ministério da Educação maior liberação de recursos, tanto humanos quanto orçamentários (BAVARESCO, 2014, p. 147)

A área que apresentava menor demanda de estrutura e com maior possibilidade de iniciar as atividades, dentro da urgência exigida pelo MEC, era a área de Matemática. Os entrevistados de Bavaresco (2014) ainda relataram que como a estrutura docente era formada basicamente por engenheiros e outros bacharéis se optou incialmente pela Licenciatura em Química, sobretudo pelo quantitativo de professores de Química já existentes, porém a instituição não possuía estrutura física suficiente, e nem tempo hábil para construção de laboratórios que suportassem um curso de Graduação. Tal fato corrobora com Arruda e Paula (2012) quando estas pesquisadoras afirmam que a escolha do curso não seguiu critérios muito claros, não partiu necessariamente de uma demanda local/regional ou da afinidade tradicional da instituição.

Segundo o pesquisador,

Analisando-se as manifestações dos entrevistados e as informações contidas em ata ${ }^{\text {xiv }}$, observa-se que a "escolha" pela Matemática, dentre as licenciaturas cogitadas, teve como fatores preponderantes as limitações estruturais e as facilidades operacionais de implantação, as quais viabilizariam o início das atividades em curto espaço de tempo, respondendo assim às pressões do Ministério da Educação pelo cumprimento dessa meta. (BAVARESCO, 2014, p. 148) 


\section{O ESTADO DO CONHECIMENTO SOBRE A FORMAÇÃO DE PROFESSORES DE MATEMÁTICA NOS INSTITUTOS FEDERAIS}

Nesse cenário, os aspectos pragmáticos e operacionais prevaleceram para atender às exigências impostas para suprir a nova demanda. Dessa forma, são operacionalizados mecanismos orientados à obtenção de resultados imediatos, numa lógica performativa das instituições e, consequentemente, do Estado, que precisa responder a essas carências do sistema educacional por meio da apresentação de dados estatísticos que evidenciam a atuação de todos em prol desses ideais.

Ao analisar o PPC deste curso em questão se observa que uma das justificativas para sua implantação é exatamente a escassez nacional de professores das áreas de Ciências e Matemática: os cursos de Licenciatura em Matemática e Física surgiram principalmente da necessidade apresentada no decorrer da década de 1990, quando foi constatado um grande déficit de professores na área de Ciências Exatas. (PPC IFRS, p. 7)

Isso faz com que aconteça um movimento do global para o local, do macro para o micro, no sentido de que uma política nacional, baseada em uma escassez não comprovada, conduza todos os projetos de curso a se basearem no mesmo argumento. Não há uma reflexão.

Destacamos também o trabalho de Silva Neto (2015), que apresentou um estudo de caso sobre a formação de professores nos cursos de Licenciatura em Matemática ofertados pelos IFs se baseando no caso do Instituto Federal Catarinense - IFC. O pesquisador estudou como esses cursos foram concebidos, o perfil esperado para os egressos e como se deu a integração entre as disciplinas matemáticas e pedagógicas. Para isso, realizou-se um estudo da legislação que trata sobre o tema das licenciaturas, da formação de professores e dos cursos superiores de matemática no Brasil.

Das 74 pesquisas analisadas, 11 se referem à formação de professores de Matemática nos IFs. Em geral as pesquisas apresentam homogeneidade no que se refere ao processo de implantação dos cursos. É uma constante também o problema da evasão nesse curso, da mesma forma como acontecia/acontece nas universidades.

A tese de Bavaresco (2014) ilustra bem o estado do conhecimento a respeito desses cursos a partir das pesquisas recentes. Uma pesquisa importante dentro campo da formação de professores no sentido de explicitar um problema local que é um reflexo de um problema global. No desenvolvimento da tese não se questionou a existência da escassez, ela é aceita incondicionalmente, é a justificativa para a implantação dos cursos de Licenciatura nos IFs. A tese, apesar de focar no movimento ocorrido durante a implantação, ela encerra discutindo as mesmas consequências já observadas nas outras pesquisas.

Revista RBBA $\mid$ Revista Binacional Brasil Argentina 


\section{O ESTADO DO CONHECIMENTO SOBRE A FORMAÇÃO DE PROFESSORES DE MATEMÁTICA NOS INSTITUTOS FEDERAIS}

\section{CONSIDERAÇÕES FINAIS}

Os Institutos Federais foram criados por Lei Federal em 2008 tendo a obrigação de ofertar $20 \%$ de suas vagas para cursos de formação de professores, prioritariamente nas áreas de Ciências e Matemática, como forma de atender ao problema da escassez de professores na Educação Básica nestas áreas, constatado pelo CNE em 2007. A partir desta Lei, dada a capilaridade dos IFs no território nacional, o número de cursos de Licenciatura nestas áreas aumentou abruptamente, em particular de Matemática.

$\mathrm{Na}$ mesma velocidade cresceram as pesquisas desenvolvidas com licenciandos, egressos, professores e gestores destes cursos, a fim de se obter as características desses cursos e assim estabelecer uma identidade, tanto para os cursos como para os IFs.

Observou-se, entretanto, que estes cursos, apesar de possuírem fatores positivos característicos dos IFs, como a oferta de educação básica e da Licenciatura em uma mesma instituição aproximando o futuro professor do seu lócus de trabalho, eles carregam os mesmos vícios dos cursos universitários, o que era de se esperar, visto que a falta de expertise dos IFs com as Licenciaturas fez com que os primeiros cursos implantados fossem cópias espelhadas dos cursos universitários, como apontam pesquisas como Azevedo (2017).

Alguns desses vícios são: as altas taxas de evasão e retenção; a falta de contextualização entre os conhecimentos pedagógicos e específicos dos cursos; a Licenciatura ser reduzida a um apêndice do bacharelado. Esta repetição dos mesmos problemas nos leva a concluir que a mudança/ampliação do lócus de oferta não resolveu os velhos problemas.

A pesquisa de doutoramento em desenvolvimento pretende pôr em xeque o que acreditamos ser a gênese desse problema, que é esta escassez de professores tão propalada em todas estas pesquisas desenvolvidas e por nós analisadas, bem como nos PPCs, documentos oficiais, nas mídias e nos discursos de gestores e políticos. O real problema ainda não foi atacado, pois ele sequer foi revelado e colocado em debate. 


\section{O ESTADO DO CONHECIMENTO SOBRE A FORMAÇÃO DE PROFESSORES DE MATEMÁTICA NOS INSTITUTOS FEDERAIS}

\section{REFERÊNCIAS}

ABRÚCIO, F.L. Formação de professores no Brasil: diagnóstico, agenda de políticas e estratégias para a mudança. São Paulo: Moderna, 2016. 112p.

ANDRÉ, M.E.D.A. Formação de professores: a constituição de um campo de estudos. Educação, Porto Alegre, v. 33, n. 3, p. 174-181, set./dez. 2010

ANTUNES SANTANA, O. Evasão nas Licenciaturas das Universidades Federais: entre a apetência e a competência. Educação, Santa Maria, vol. 41, núm. 2, p. 311-327, maio-agosto, 2016. Disponível em https://www.redalyc.org/articulo.oa?id=117146405004. Acesso em 30 abril 2020.

ARRUDA, M.C.C.; PAULA, L.A.L. Os Institutos Federais como instituição formadora de professores: expectativas e contradições. In: Encontro Nacional de Didática e Práticas de Ensino - ENDIPE, XVI, 2012, Campinas. Anais... Campinas: FE/UNICAMP, 2012, Livro 1, p. $1581-1592$

AZEVEDO, A. P. L. Ensino médio integrado à educação profissional: formação omnilateral ou unilateral? 2017. 134 f. Dissertação (Mestrado em Educação) - Faculdade de Educação, Universidade Federal do Ceará, Fortaleza.

BAVARESCO, D. Política de Formação de Professores nos Institutos Federais e a Licenciatura em Matemática no IFRS - Câmpus Bento Gonçalves. 2014. 225 f. Tese (Doutorado em Educação) - Universidade do Vale do Rio dos Sinos, São Leopoldo.

BRASIL. Decreto 3462, de 17 de maio de 2000. Dá nova redação ao art. $8^{\circ}$ do Decreto Federal $\mathrm{n}^{\circ}$ 2.406/97 (trata da autonomia dos Centros Federais de Educação Tecnológica). Disponível em: http://www.planalto.gov.br/ccivil_03/decreto/d3462.htm. Acesso em: 30 abril 2020.

BRASIL. Decreto 5225, de $\mathbf{1}^{\circ}$ de outubro de 2004. Altera dispositivos do Decreto 3.860 , de 9 de julho de 2001, que dispõe sobre a organização do ensino superior e a avaliação de cursos e instituições, e dá outras providências. Disponível em: http://www.planalto.gov.br/ccivil_03/_Ato2004-2006/2004/Decreto/D5225.htm. Acesso em: 30 abril 2020.

BRASIL. Decreto 6094, de 24 de abril de 2007a. Dispõe sobre a implementação do Plano de Metas Compromisso Todos pela Educação, pela União Federal, em regime de colaboração com Municípios, Distrito Federal e Estados, e a participação das famílias e da comunidade, mediante programas e ações de assistência técnica e financeira, visando a mobilização social pela melhoria da qualidade da educação básica. Disponível em: http://www.planalto.gov.br/ccivil_03/_Ato2007-2010/2007/Decreto/D6094.htm. Acesso em: 30 abril 2020.

BRASIL. Lei $\mathbf{n}^{\circ}$ 9394, de 20 de dezembro de 1996. Estabelece as diretrizes e bases da educação nacional. Disponível em: http://www.planalto.gov.br/ccivil_03/leis/19394.htm. Acesso em: 30 abril 2020.

BRASIL. Lei $\mathbf{n}^{\mathbf{0}}$ 11.892, de 29 de dezembro de 2008. Institui a Rede Federal de Educação Profissional e Tecnológica, cria os Institutos Federais de Educação, Ciência e Tecnologia. 


\section{O ESTADO DO CONHECIMENTO SOBRE A FORMAÇÃO DE PROFESSORES DE MATEMÁTICA NOS INSTITUTOS FEDERAIS}

Disponível em: http://www.planalto.gov.br/ccivil_03/_Ato2007-2010/2008/Lei/L11892.htm. Acesso em: 30 abril 2020.

BRASIL. Lei no 13.005, de 25 de junho de 2014. Aprova o Plano Nacional de Educação - PNE e dá outras providências. Disponível em: http://www.planalto.gov.br/ccivil_03/_ato20112014/2014/lei/113005.htm. Acesso em: 30 abril 2020.

BRASIL. Ministério da Educação. Portaria 432, de 19 de julho de 1971. Normas para organização curricular do Esquema I e do Esquema II. Brasília: MEC, 1971.

BRASIL. Ministério da Educação. Conselho Nacional de Educação. Escassez de Professores no Ensino Médio: Propostas estruturais e emergenciais. Brasília: CNE/CEB, 2007b.

CIAVATTA, M. Os Centros Federais de Educação Tecnológica e o Ensino Superior: duas lógicas em confronto. Educ. Soc., Campinas, vol. 27, n. 96 - Especial, p. 911-934, out. 2006. Disponível em: http://www.scielo.br/pdf/es/v27n96/a13v2796.pdf Acesso em 30 abril 2020.

FLACH, A. Formação de Professores nos Institutos Federais: estudo sobre a implantação de um curso de Licenciatura em um contexto de transição institucional. 2014. 210 f. Tese (Doutorado em Educação) - Universidade do Vale do Rio dos Sinos, São Leopoldo.

FREITAS, H.C.L. A reforma do Ensino Superior no campo da formação dos profissionais da educação básica: As políticas educacionais e o movimento dos educadores. Educação \& Sociedade. Campinas, vol. 20, n. 68, p. 17-44, dez. 1999. Disponível em: http://www.scielo.br/pdf/es/v20n68/a02v2068.pdf. Acesso em: 30 de abril de 2020.

GATTI, B.A.; BARRETO, E.S.S. Professores do Brasil: impasses e desafios. Brasília: UNESCO, 2009. 294p.

GATTI, B.A.; BARRETO, E.S.S.; ANDRÉ, M.E.D.A.; ALMEIDA, P.C.A. Professores do Brasil: novos cenários de formação. Brasília: UNESCO, 2019. 351p.

GONÇALVES, I.L. Taxa de evasão e impacto financeiro na realidade da Unifal-MG. 2018. 134 f. Dissertação (Mestrado em Administração Pública) - Universidade Federal de Alfenas, Varginha.

INSTITUTO FEDERAL DE EDUCAÇÃO, CIÊNCIA E TECNOLOGIA DO RIO GRANDE DO SUL. Projeto Pedagógico: Licenciatura em Matemática. Bento Gonçalves: IFRS, 2017.

LIMA, F.B.G. A Formação de professores nos Institutos Federais de Educação, Ciência e Tecnologia: Um estudo da concepção política. 2012. 282 f. Dissertação (Mestrado em Educação) - Faculdade de Educação, Universidade de Brasília, Brasília.

LIMA, F.B.G. A Formação de professores nos Institutos Federais de Educação, Ciência e Tecnologia: Um estudo da concepção política. Natal, RN: IFRN, 2014. 94p.

MORAES, G.H. Identidade de Escola Técnica vs. Vontade de Universidade - A Formação da Identidade dos Institutos Federais. 2016. 356 f. Tese (Doutorado em Educação) Universidade de Brasília, Brasília. 


\section{O ESTADO DO CONHECIMENTO SOBRE A FORMAÇÃO DE PROFESSORES DE MATEMÁTICA NOS INSTITUTOS FEDERAIS}

MOURA, D.H. Educação básica e educação profissional e tecnológica: dualidade histórica e perspectivas de integração. Holos, Natal, v. 2, ano 23, 2007. Disponível em: http://www2.ifrn.edu.br/ojs/index.php/HOLOS/article/viewFile/11/110. Acesso em 30 abril 2020.

REIS, A.G. Representações sociais dos professores formadores do IFAM: Discutindo o conceito de professor reflexivo como quebra de paradigma. 2017. $291 \mathrm{f}$. Tese (Doutorado em Educação) - Pontifícia Universidade Católica de Minas Gerais, Belo Horizonte.

SILVA, I.B.G. Contexto da educação profissional e tecnológica no Brasil: Olhares sobre Licenciaturas. 2017. 204 f. Tese (Doutorado em Educação) - Pontifícia Universidade Católica de Goiás, Goiânia.

SILVA NETO, O. A Formação dos Professores de Matemática no Instituto Federal Catarinense. 2015. 138 f. Dissertação (Mestrado Profissional em Ensino de Matemática) Instituto de Matemática, Universidade Federal do Rio Grande do Sul, Porto Alegre.

TURMENA, L.; AZEVEDO, M.L.N. A expansão da Rede Federal de Educação Profissional, Científica e Tecnológica: os Institutos Federais em questão. Rev. Diálogo Educ., Curitiba, v. 17, n. 54, p. 1067-1084, jul./set. 2017. Disponível em: https://periodicos.pucpr.br/index.php/dialogoeducacional/article/view/21938. Acesso em 30 abril 2020.

VERDUM, P. L. Formação inicial de professores para a educação básica, no contexto dos IFs: propondo indicadores de qualidade, a partir de um estudo de caso no IFRS. 2015. $281 \mathrm{f}$. Tese (Doutorado em Educação) - Faculdade de Educação, Pontifícia Universidade Católica do Rio Grande do Sul, Porto Alegre.

\section{SOBRE OS AUTORES}

Leandro de Jesus Dueli é Doutorando em Ciências da Educação pela Universidade de Santiago de Compostela (USC). Mestre em Matemática pela Universidade Federal de Juiz de Fora (2013). Graduado/Licenciado em Matemática pela Universidade Federal de Ouro Preto (2008). É professor ensino básico, técnico e tecnológico do Instituto Federal de Educação Ciência e Tecnologia de Goiás - Campus Goiânia/Oeste, atuando na Educação de Jovens e Adultos, Ensino Técnico Integrado ao Ensino Médio e Ensino Superior.

Endereço eletrônico: leandro.dueli@gmail.com https://orcid.org/0000-0003-0548-3673 


\section{O ESTADO DO CONHECIMENTO SOBRE A FORMAÇÃO DE PROFESSORES DE MATEMÁTICA NOS INSTITUTOS FEDERAIS}

Simone Ariomar de Souza é Doutora em Educação (2015) pela Pontifícia Universidade Católica de Goiás (PUC/GO), possui mestrado (2002) e graduação (1999), ambos em Matemática pela Universidade Federal de Goiás (UFG). É professora efetiva da área de matemática sob regime de dedicação exclusiva no Instituto Federal de Goiás/Campus Goiânia. Atua em cursos do ensino médio integrado ao técnico nas modalidades regular e EJA; cursos de graduação e pós-graduação (Especialização em Matemática). Tendo defendido doutorado na linha de Teorias da Educação e Processos Pedagógicos, desenvolve pesquisas em matemática e também pesquisas fundamentadas na teoria histórico-cultural, com ênfase no processo de ensino-aprendizagem em matemática. Além disso, possui ampla experiência no ensino básico, técnico, tecnológico e superior.

Endereço eletrônico: sariomars@ gmail.com https://orcid.org/0000-0003-4977-8879

Maria Jesus Salinas Portugal es Profesora Titular de Didáctica de la Matemática (jubilada) de la Universidad de Santiago de Compostela (USC). Licenciada en C. Matemáticas por la USC, Doctora en Pedagogía por la USC. Maestra de Primaria. Autora de libros y artículos en revistas del ámbito nacional e internacional. Coordinadora del grupo de investigación en educación infantil de la Sociedad Española de Investigación en Educación Matemática. Líneas de investigación: Conocimiento y desarrollo profesional del profesor de matemáticas, Buenas prácticas matemáticas en la Educación Infantil y Estímulo Matemático para una Educación Inclusiva. Impartió docencia en el Programa de Doctorado en Didáctica de las Ciencias Experimentales y de la Matemática, y del que formó parte como miembro de la comisión científica.

Endereço eletrônico: mjesus.salinas@usc.es

https://orcid.org/0000-0003-1029-2433

\section{Notas}

i Conferência realizada em Jomtien - Tailândia em 1990, articulada por organismos internacionais multilaterais, tendo entre seus objetivos a universalização da educação e a erradicação do analfabetismo.

ii A LDB, Lei 9394/1996 (BRASIL, 1996), foi sancionada bastante arraigada no relatório da Conferência de Jomtien. Esta Lei estabelece as Diretrizes e Bases da Educação nacional, constituindo um novo marco na história da educação brasileira, e em particular para a formação de professores ao tornar obrigatória a formação superior para o exercício da profissão docente.

iii Todos os programas podem ser consultados na página do MEC http://portal.mec.gov.br/publicacoes-paraprofessores?id=15944:programas-do-mec-voltados-a-formacao-de-professores. Acesso em 11/10/19.

Revista RBBA $\mid$ Revista Binacional Brasil Argentina 


\section{O ESTADO DO CONHECIMENTO SOBRE A FORMAÇÃO DE PROFESSORES DE MATEMÁTICA NOS INSTITUTOS FEDERAIS}

\footnotetext{
iv Apesar de lançado oficialmente em 2007, as ações desse programa iniciaram em 2003, ainda no primeiro mandado do governo Lula.

v O CEFET-PR foi o único a se tornar Universidade Tecnológica, em 2005.

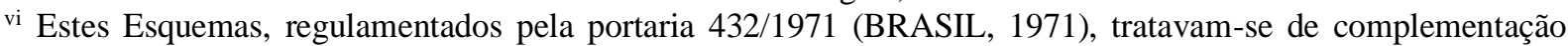
pedagógica para portadores de diplomas de nível superior e portadores de diploma técnico industrial de nível médio. Apesar do caráter emergencial, esta portaria só foi revogada em 1997.

vii Segundo este Decreto, os CEFETs passaram o gozar de autonomia para a criação de cursos e ampliação de vagas nos níveis básico, técnico e tecnológico da Educação Profissional, bem como para implantação de cursos de formação de professores para as disciplinas científicas e tecnológicas do Ensino Médio e da Educação Profissional. viii Dos 38 IFs, apenas 3 não ofertavam Licenciatura em Química em nenhum campus em 2018, segundo a Plataforma Nilo Peçanha - PNP.

ix Os números de concluintes podem ser obtidos tanto no Censo da Educação Superior, que é divulgado anualmente pelo Instituto Nacional de Estudos e Pesquisas Educacionais Anísio Teixeira- INEP, quanto pela Plataforma Nilo Peçanha - PNP.

${ }^{x}$ De acordo com o MEC, já passa de 660 o número de unidades (consulta realizada em 30/09/2019)

xi Ao longo do ano de 2019 foram implantados cursos de Licenciatura em Matemática em mais 8 unidades dos IFs: Caucaia e Maracanaú (IFCE), João Pessoa (IFPB), São Paulo do Potengi (IFRN), Santa Maria da Boa Vista (IFSertãoPE), Salto (IFSP), Frederico Westphalen (IFFarroupilha) e Capanema (IFPR). Em dezembro de 2019 já são 99 cursos contabilizados, distribuídos em 34 IFs.

xii Este importante documento norteador, proposto no encerramento do I Fórum Nacional das Licenciatura dos Institutos Federais (2010), contêm as recomendações dos participantes, no que se refere a gestão, infraestrutura, formação de professores e questões pedagógicas necessárias aos cursos de licenciaturas dos Institutos Federais. Esta Carta pode ser conferida integralmente em Flach (2014, pp. 197-201) e Silva (2017, pp. 202-204)

xiii Esse termo é utilizado por Moraes (2016) para designar os professores das antigas ETFs e CEFETs.

${ }^{\text {xiv }}$ Refere-se às atas do Conselho Diretor do antigo CEFET - BG.
}

Recebido em: 03/05/2020

Aprovado em: 27/05/2020

Publicado em: 01/07/2020 